\title{
The encephalopathy of congenital heart disease
}

\author{
J. William Gaynor, MD
}

See related articles on pages 2181-8 and 2190-9.

In the United States, approximately 1 in every 100 neonates has congenital heart disease (CHD) diagnosed, and many (25\%-35\%) have critical CHD necessitating heart surgery soon after birth. As recently as the 1960 s, only $20 \%$ of neonates with critical CHD survived to adulthood. Today, thanks to better diagnostic technologies and methods (including prenatal diagnosis), advances in surgery, and improved postoperative care, early survival is greater than $90 \%$. Coincident with improved early outcomes, there has been a sobering recognition of the ongoing risk of late mortality, as well as significant morbidity, for these children. In particular, neurodevelopmental disability is now recognized as the most common long-term complication of critical CHD and has the most negative impact on quality of life, academic performance, and opportunity for independence as an adult.

Most studies of neuroprotection in the CHD population have focused on the intraoperative period and management of cardiopulmonary bypass. There is little evidence, however, that these strategies have yielded significant improvements in neurodevelopmental outcomes. A recent analysis of more than 1700 patients born 1996 to 2009 who underwent cardiac surgery at younger than 9 months demonstrated only modest improvement in early neurodevelopment outcomes since 1996, even after adjustment for patient factors. ${ }^{1}$ A systematic review of current practices for neuromonitoring and neuroprotection during cardiac surgery in infants found that the level of evidence is insufficient to support the effectiveness of any of the currently used neuroprotective therapies. $^{2}$ These findings suggest that a new approach and new targets for neuroprotection are essential to improve outcomes.

Patient and environmental factors, such as prematurity, genetic syndromes, and socioeconomic status, are likely more important determinants of neurodevelopmental outcomes than are operative management strategies. ${ }^{3-5}$ In addition, there is an increasing body of evidence that

From the Department of Pediatric Cardiothoracic Surgery, The Children's Hospital of Philadelphia, Philadelphia, Pa.

Disclosures: Author has nothing to disclose with regard to commercial support. Received for publication Sept 22, 2014; accepted for publication Sept 22, 2014.

Address for reprints: J. William Gaynor, MD, The Children's Hospital of Philadelphia, Pediatric Cardiothoracic Surgery, 34th St and Civic Center Blvd, Philadelphia, PA 19104 (E-mail: gaynor@email.chop.edu).

J Thorac Cardiovasc Surg 2014;148:1790-1

$0022-5223 / \$ 36.00$

Copyright (c) 2014 by The American Association for Thoracic Surgery

http://dx.doi.org/10.1016/j.jtcvs.2014.09.061 altered fetal hemodynamics secondary to CHD lead to decreased blood flow or oxygen delivery to the fetal brain, resulting in impaired brain growth and altered structural and cellular maturation, particularly of the white matter. Magnetic resonance imaging (MRI) studies in CHD fetuses show smaller gestational age- and weightadjusted total brain volumes and abnormal brain metabolism, as well as delayed cortical development and folding. ${ }^{6-10}$ At birth, brain maturation in neonates with hypoplastic left heart syndrome or transposition of the great arteries is delayed by approximately 1 month relative to a normative sample. ${ }^{8}$ Postnatal MRI studies have shown that white matter injury is evident in as many as $20 \%$ of infants before cardiac surgery and in $40 \%$ to $50 \%$ early in the postoperative period. ${ }^{11-15}$ Andropoulos and colleagues ${ }^{4}$ showed that a lower brain maturity score at birth by MRI is associated with greater brain injury in both the preoperative and postoperative periods. Beca and associates ${ }^{15}$ recently reported that severity of brain immaturity at birth predicts the severity of neurodevelopmental impairment at 2 years of age after cardiac surgery in infancy. Thus altered brain development secondary to CHD may increase vulnerability to perioperative hemodynamic instability and hypoxic or ischemic injury. There appear to be long-lasting consequences of this abnormal brain development and white matter injury. For example, von Rhein and colleagues ${ }^{16}$ showed that brain volumes remain smaller into adolescence and that the magnitude of reduction correlates with neurodevelopmental outcomes. Rollins and coworkers ${ }^{17}$ recently evaluated the neurodevelopmental impact of white matter injury and abnormal white matter microstructure in adolescents with transposition of the great arteries enrolled in the Boston Circulatory Arrest Study. They found that regional alternations in white matter microstructure, as assessed by MRI and diffusion tensor imaging, were correlated with performance for mathematics achievement, inattention, executive function, visual and spatial skills, and memory.

Two articles in this issue of the Journal provide important additions to the growing body of data linking CHD, abnormal brain development, white matter injury, and the risk of long-term neurodevelopmental disability. Heinrichs and colleagues ${ }^{18}$ from Aachen correlated structural brain abnormalities identified by MRI with neurodevelopmental outcomes in adolescent survivors of the arterial switch operation. Moderate to severe structural abnormalities were found in $32 \%$ of subjects. White matter injury, characterized by periventricular leukomalacia, was present in more than $50 \%$ of subjects. Greater severity of white matter injury correlated with worse neurodevelopment impairment. 
Importantly, preoperative acidosis and hypoxia were the only independent patient-related risk factors for neurologic dysfunction, reduced intelligence, periventricular leukomalacia, and reduced brain volume. Operative management factors, including duration of deep hypothermic circulatory arrest, were not significant predictors of outcome. Lynch and associates $^{19}$ from our group in Philadelphia provided additional evidence that preoperative factors are important determinants of the risk of perioperative white matter injury. Novel optical imaging strategies were used to assess preoperative and postoperative cerebral hemodynamics in neonates undergoing stage 1 reconstruction for hypoplastic left heart syndrome. Consistent with previous studies, new or worsened white matter injury was identified by MRI in almost $50 \%$ of patients after surgery. Importantly, the risk of acquired post-operative white matter injury was highly correlated with longer time between birth and surgery, whereas perioperative and postoperative variables did not predict injury. These findings, which must be validated, suggest that changes in cerebral hemodynamics and cerebral oxygen metabolism after birth may be important modifiers of the risk of perioperative white matter injury in some neonates with CHD. Further studies are needed before it can be concluded that strategies to modify cerebral blood flow before surgery or altering the time of surgery will lead to decreased brain injury and improved neurodevelopmental outcomes.

In summary, there is growing evidence that abnormal brain development beginning in utero and the resultant brain immaturity at birth are primary major risk factors underlying perioperative hypoxic/ischemic white matter brain injury and subsequent neurodevelopmental disability seen in more than $50 \%$ of neonates after surgery for CHD. These findings support the hypothesis that the presence of CHD leads to a complex combination of developmental abnormalities in the brain and direct brain injury secondary to hypoxia or ischemia, especially to the developing white matter. ${ }^{20}$ Volpe $^{20}$ has noted that this pattern of destructive and developmental disturbances is similar to the brain injury found in infants born prematurely and coined the term "encephalopathy of CHD." The current body of evidence suggests that neuroprotective strategies initiated at the time of cardiac surgery, although potentially important to prevent further injury, are inadequate to improve the neurodevelopmental outcomes significantly for these patients. To optimize brain development, prevent brain injury, and improve neurodevelopmental outcomes for these vulnerable infants, strategies to provide neuroprotection and enhance neuroplasticity may need to be initiated before birth.

\section{References}

1. Gaynor JW, Stopp C, Wypij D, Andropoulos DB, Atallah J, Beca J, et al; International Cardiac Collaborative on Neurodevelopment (ICCON) Investi- gators; Pediatric Heart Network (PHN) Investigators. Early neurodevelopmental outcomes after cardiac surgery in infancy have not improved: a multi-center retrospective analysis of 1,718 patients. Circulation. 2012;126: A12437.

2. Hirsch JC, Jacobs ML, Andropoulos D, Austin EH, Jacobs JP, Licht DJ, et al. Protecting the infant brain during cardiac surgery: a systematic review. Ann Thorac Surg. 2012;94:1365-73; discussion 1373.

3. Gaynor JW, Wernovsky G, Jarvik GP, Bernbaum J, Gerdes M, Zackai E, et al. Patient characteristics are important determinants of neurodevelopmental outcome at one year of age after neonatal and infant cardiac surgery. $J$ Thorac Cardiovasc Surg. 2007;133:1344-53. 1353.e1-3.

4. Atallah J, Dinu IA, Joffe AR, Robertson CM, Sauve RS, Dyck JD, et al. Two-year survival and mental and psychomotor outcomes after the Norwood procedure: an analysis of the modified Blalock-Taussig shunt and right ventricle-to-pulmonary artery shunt surgical eras. Circulation. 2008;118:1410-8.

5. Atallah J, Joffe A, Robertson CM, Leonard N, Blakley PM, Nettel-Aguirre A, et al. Two-year general and neurodevelopmental outcome after neonatal complex cardiac surgery in patients with deletion 22q11.2: a comparative study. J Thorac Cardiovasc Surg. 2007;134:772-9.

6. Miller SP, McQuillen PS, Hamrick S, Xu D, Glidden DV, Charlton N, et al. Abnormal brain development in newborns with congenital heart disease. $N$ Engl J Med. 2007;357:1928-38.

7. Limperopoulos C, Tworetzky W, McElhinney DB, Newburger JW, Brown DW, Robertson RL Jr, et al. Brain volume and metabolism in fetuses with congenital heart disease: evaluation with quantitative magnetic resonance imaging and spectroscopy. Circulation. 2010;121:26-33.

8. Licht DJ, Shera DM, Clancy RR, Wernovsky G, Montenegro LM, Nicolson SC, et al. Brain maturation is delayed in infants with complex congenital heart defects. J Thorac Cardiovasc Surg. 2009;137:529-36; discussion 536-7.

9. Clouchoux C, Kudelski D, Gholipour A, Warfield SK, Viseur S, BouyssiKobar M, et al. Quantitative in vivo MRI measurement of cortical development in the fetus. Brain Struct Funct. 2012;217:127-39.

10. Ortinau C, Beca J, Lambeth J, Ferdman B, Alexopoulos D, Shimony JS, et al. Regional alterations in cerebral growth exist preoperatively in infants with congenital heart disease. J Thorac Cardiovasc Surg. 2012;143: 1264-70.

11. Mahle WT, Tavani F, Zimmerman RA, Nicolson SC, Galli KK, Gaynor JW, et al An MRI study of neurological injury before and after congenital heart surgery. Circulation. 2002;106(12 Suppl 1):I109-14.

12. Galli KK, Zimmerman RA, Jarvik GP, Wernovsky G, Kuypers MK, Clancy RR, et al. Periventricular leukomalacia is common after neonatal cardiac surgery. $J$ Thorac Cardiovasc Surg. 2004;127:692-704. Erratum in: J Thorac Cardiovasc Surg. 2004;128:498.

13. Licht DJ, Wang J, Silvestre DW, Nicolson SC, Montenegro LM, Wernovsky G, et al. Preoperative cerebral blood flow is diminished in neonates with severe congenital heart defects. J Thorac Cardiovasc Surg. 2004;128:841-9.

14. Andropoulos DB, Hunter JV, Nelson DP, Stayer SA, Stark AR, McKenzie ED, et al. Brain immaturity is associated with brain injury before and after neonatal cardiac surgery with high-flow bypass and cerebral oxygenation monitoring. $J$ Thorac Cardiovasc Surg. 2010;139:543-56.

15. Beca J, Gunn JK, Coleman L, Hope A, Reed PW, Hunt RW, et al. New white matter brain injury after infant heart surgery is associated with diagnostic group and the use of circulatory arrest. Circulation. 2013;127:971-9.

16. von Rhein M, Buchman A, Hagmann C, Huber R, Klaver P, Knirsch W, et al Brain volumes predict neurodevelopment in adolescents after surgery for congenital heart disease. Brain. 2014;137:268-76.

17. Rollins CK, Watson CG, Asaro LA, Wypij D, Vajapeyam S, Bellinger DC, et al. White matter microstructure and cognition in adolescents with congenital heart disease. J Pediatr. September 9, 2014 [Epub ahead of print].

18. Heinrichs AK, Holschen A, Krings T, Messmer BJ, Schnitker R, Minkenberg R, et al. Neurologic and psycho-intellectual outcome related to structural brain imaging in adolescents and young adults after neonatal arterial switch operation for transposition of the great arteries. J Thorac Cardiovasc Surg. 2014;148:2190-9.

19. Lynch JM, Buckley EM, Schwab PJ, McCarthy AL, Winters ME, Busch DR, et al. Time to surgery and preoperative cerebral hemodynamics predict postoperative white matter injury in neonates with hypoplastic left heart syndrome. J Thorac Cardiovasc Surg. 2014;148:2181-8.

20. Volpe JJ. Encephalopathy of congenital heart disease - destructive and developmental effects intertwined. J Pediatr. 2014;164:962-5. 